\title{
Proceeding
}

Supplementary Issue: Spring Conferences of Sports Science. 15th Convention and Workshop of the International Network of Sport and Health Science, 5-8 June 2019. University of Las Palmas de Gran Canaria, Las Palmas de Gran Canaria, Spain.

\section{Augmented, virtual and robotics reality for distance learning and internship in telematics Sport and Exercise Science degrees in Italy}

\author{
FRANCESCA D'ELIA ${ }^{1} \triangle$, FRANCESCO PELUSO CASSESE ${ }^{2}$, TIZIANA D'ISANTO ${ }^{1}$ \\ 1 University of Salerno, Italy \\ 2Online University Niccolò Cusano, Italy
}

\begin{abstract}
Sport and Exercise Science degrees has special purposes because the curricula provide, in relation to specific aims, the deepening of some lessons and activities, with internship traditionally playing in facilities, training and sport organizations, businesses, administration structures and laboratories, in addition to visits of study at other national and foreign universities, including in the framework of international exchange about teaching and research. The distance education methods in e-learning university has been continuously developed but doesn't provide the whole solution for the physical and sport activities in Exercise and sport sciences degrees, including the internship and works. The aim is to search and carry out the technological products to help the development of peculiarity aspects of the practice to achieve the target. Utilizing the archive research method and the technological based evidences could be make a hypothesis to improve the current vision with augmented, virtual and robotics reality applied to education distance. In this way the main technologies, such as Nintendo, PS, Xbox and others, could be utilized for enlarge the education opportunities for special needs people, included the disabled people. For the law aspects have to consider the specific mode to validate the activity in the same manner to play currently with an appropriate rule modification. Keywords: Online university; Teaching models; Motor learning.
\end{abstract}

\section{Cite this article as:}

D'Elia, F., Cassese, F.P., \& D'Isanto, T. (2019). Augmented, virtual and robotics reality for distance learning and internship in telematics Sport and Exercise Science degrees in Italy. Journal of Human Sport and Exercise, 14(4proc), S792-S796. doi:https://doi.org/10.14198/hse.2019.14.Proc4.41

Corresponding author. University of Salerno, Italy.

E-mail: fdelia@unisa.it

Supplementary Issue: Spring Conferences of Sports Science. 15th Convention and Workshop of the International Network of Sport and Health Science, 5-8 June 2019. University of Las Palmas de Gran Canaria, Las Palmas de Gran Canaria, Spain. JOURNAL OF HUMAN SPORT \& EXERCISE ISSN 1988-5202

(c) Faculty of Education. University of Alicante doi:10.14198/jhse.2019.14.Proc4.41 


\section{INTRODUCTION}

In Italy until the end of 20th Century the highest level of training in physical education field was managed by the High Institute of Physical Education (ISEF) where the teaching/learning was mainly focused on practice activities. The main purpose of the ISEF was to promote the progress of sciences applied to physical education and to provide the scientific basic and technical culture for the preparation and improvement of those who wished to dedicate themselves to the teaching of physical education and to technical employments in the sport field, and for over fifty years they have represented the only training path to teach physical education in the high (first and second grade) school, while CONI (National Olympic Italian Committee) and the National Sport Federations directed the other training activities into the sport field (D'Elia et al., 2018; Sanseviero, 2019). In 1998 the legislative decree n. 178 provided the "Transformation of the high institutes of physical education in faculties and degree courses in Sport and Exercise Sciences". This transformation led to a diversification of curricula because of new professional profiles. Nowadays, Sport and Exercise Sciences degrees are not limited to train physical education teacher (it is needed a master's degree and a specialization course), but they offer curricula aimed for training of various graduation profiles for job positions in management of sport, sport science and adapted physical activity and sport (D'Elia, 2019).

\section{Traditional and online Sport and Exercise Sciences degrees}

Since 1998 degree courses have been adapted to the University reforms (D'Isanto, 2019, Raiola et al. 2018) and currently Italian Universities offer 92 degree courses in Sport and Exercise Sciences (38 bachelor's degrees and 54 master's degrees) mainly based on traditional teaching/learning methods and only 4 universities with 7 degrees course (4 bachelor's degree and 3 master's degrees) based on online teaching. In Italy the early online Universities have been established in 2006. These universities foster innovative learning modalities, developing research strategies for most advanced technological solutions and integrating non-residential communication tools, such as e-learning, videoconference, mobile learning and completed with special activities like workshops and seminars. These online activities replaced every subject with no need of any special obligation law, to enhance the expertise of high-school students in physical education and sport. However, online universities could also implement bachelor's and master's degree in physical education and sport, because of the lack of obligation within these activities.

A peculiarity of Sport and Exercise Science degrees is that "special purposes. The curricula of degree courses of physical activities and sport class provide, in relation to specific goals, the enhancement of some lessons and activities, with placements of facilities, training and sport organizations, businesses, public administration structures and laboratories; in addition to that, we offer exchange programs at other Italian and foreign universities, included in the framework of international agreements" (Ministerial Decree 2004). After the new ministerial degree 16 March 2007 (about bachelor's and master's degrees), this improves the subject more than the last one did: giving not less of 25 University Credits in physical education and sport in the form of internships and practical work conducted in appropriate facilities to develop motor and sport skills.

Because of different methods between online and traditional degree courses, the aim is to identify a mainstream to:

- Realize the online activities in substitution of the presence activities ones.

- Realize a practical activity and training skills using the online university with the application of new technologies through the reality increased, the virtual reality and robotic. 
- Involve new technological theories in compliance with the law and to give an optimum educational offer to students and, so, how it is possible to solve a controversial application of the laws with the mix mode teaching: face-to-face activity and in distance one.

\section{METHOD}

This study is based on an argumentative theoretical study in two steps. First, documental research with the juridical approach to analyse and examine the old rules and the new ones upon accreditation of degree courses, the rules of online university and then to verify the whole application of them. Secondly, basic research on new technologies on virtual environment and its form to interface in human movement. The results come out from the integration of the two steps.

\section{RESULTS}

By reading the laws (Ministerial Decree 2005, 2007, 2002, 2000; Law 2003), it compliances to implement a correct way to make a placement planning for bachelor's and master's degree courses in total respect and its mission statement of the online university. We are going to find a solution for these academic activities and to adopt correct process in comply to law.

The perspective of using computer games in virtual environment to educate and train of complex skills is in large diffusion also for mental training methods at high performance. It gives examples from the development of an attention trainer for piloting skills, cognitive trainer for basketball, volleyball and, a recent effort to develop a cognitive trainer, ice hockey. If this teaching method and useful tools is good for high sport performance, why isn't it used in education and training for teachers and coaches? The current theory of motor control system has a significance analogy with the mechanisms and processes of these technologies, particularly the closed loop theory by Jack Adams and the open loop theory by Richard Schmidth and of others scientists about body movement and cognition (Ceciliani, 2019, Ceciliani et al, 2005, Raiola, 2017, Raiola, Di Tore, 2017, Raiola, 2013, Schimdt, Wrisberg, 2008). These give some practice responses to how the mind can work when it has merged in virtual environment. Actually, motor imagery theory, which is the theory that substances the mirror neurons system in those movement that needs of an anticipating decision. Furthermore, it talks on the other theory system that is the future development in the virtual environment (Di Tore, Raiola, 2012ab). With an appropriate education and training, it can use the neural network theory. It is possible to establish deductive rules of an expert system for the prediction of the opponent's move, into a direct confrontation for the fight activities and sports game. Training enables students to use the motor schemes that they acquired during their training (perceptual affordances).

Special tools, as haptics, with its kinaesthetic haptic interfaces, and tactile actuators could be the properly solution for the activity that is both with in presence and without physical presence. Particularly, with the term haptics we refer to a set of hardware and software technologies able to elaborate in a way different from the human mind, and so to elicit in the humans' physical perceptions through the sense of touch. Haptics is a match between human and machine by interaction technology that promises to greatly improve the communication capability with remote and/or virtual worlds, adding the sense of touch to the communication channels, beside the conventional ones based on the hearing and sighting sense. Reflecting to the humans the physical stimulations arising from the contact with virtual or remote objects allows a natural control of the interaction, during, for example, the execution of manipulative or exploration tasks. Differently from the case of visual and audio communication, the optimizing of the physical sensation relating to the sense of touch requires the set-up of a two way real-time communication with the remote or virtual world. Indeed, the physical 
stimulations of the haptics sensorial system is a direct consequence of the actions performed on the environment. From the technology point of view, the research is primarily focused on the identification and development of suitable sensing and actuation technologies able, from one side, to acquire the movements of the human limbs, that are fed as an input to the system, and, from the other side, to fed to the human the corresponding stimulations, as an output from the system. The devices able to embody these two basic functionalities are named Haptic Interfaces. The research on virtual world is focused in the development of mathematical models and related computing architectures and techniques, able to evaluate in real time the response of the environment to the actions of the human. The set of these software technologies are indicated with the generic term of Haptic Rendering. Furthermore Kinesthetic Haptic Interfaces (KHI) are a class of haptic interface able to exert controlled forces on the human body using as an End Effectors a passive connection part that is permanently in contact with the limb(s) of the operator during both the time in which no contact with the Kinesthetic Haptic Interfaces (KHI) are a class of haptic interface able to exert controlled forces on the human body using as an End Effectors a passive connection part that is permanently in contact with the limb(s) of the operator during both the time in which no contact with the remote or virtual object is established and the time in which the contact is established. The connection part can imitate the shape of a specific tool, like for example a cutter, or be conformed to adhere to the limb surface, like for example in the case of a thimble. KHI allows a satisfactory simulation of interaction with objects that are mediated by the interposition of specific tool (case of indirect contact), as for example in the case of the simulation of a surgical procedure, even if they are currently used also for the simulation of direct contact with the objects. Due to their working principle, i.e. the fact that the device is permanently attached to the operator, a special care has to be devoted to their mechanical design and to the development of their low level controller in order to guarantee the exertion of low resistance forces felt by the operator during his/her free movements (i.e. when no contact with the remote or virtual object is established). This quality of the KHI is indicated as "transparency" of the KHI and it translates in a set of mechanical performances evaluated at the end effectors of the device such as low reflected inertia, low friction and little backlash. Other performances are used to assess the quality of a $\mathrm{KHI}$, such as stiffness and bandwidth that refer to its ability to reproduce statically stiff environment and fast evolving events such as shocks or collision. They said performances of a KHI deeply depend on the kinematics of the device, the positioning and the selection of the basic components of the actuation system and the material and geometry of the links as well as by the gravity, friction and inertia compensation techniques used in the low level controller.

Finally, the tactile actuators are systems that are involved in several application fields (medicine, industry, entertainment, cultural heritage) with purposes of training, rehabilitation, simulation and so on. The full immersion, or the "being there" feeling, depends on the richness and complexity of the set of sensorial stimuli that the user receives from the VR device. The sense of Touch is one of the most important in simulation of object exploration and manipulation.

\section{CONCLUSIONS}

The students will reproduce - with growing precision - athletic gestures that allow performing certain actions during the activity. The increasing of the accuracy in the execution irreparably leads to a decrease in the movement flexibility because - in order to achieve the expected result - it cannot coexist with different execution modalities. The students can use the expert system and the use of it is useful to simulate the opponent's possible actions and prevent their effects. An expert system is a program that can implement procedures in response to a problematic situation. The purpose of an expert system is to provide an answer to the problem. In this sense the rigidity models the response situation of the student over time. More specifically, an expert system requires a set of well-defined rules, in order to build logical sequences that lead 
to the identification of the solution. Finally it is possible to discuss in order to plan the virtual environment in education for physical education and sport.

\section{REFERENCES}

Ceciliani, A. (2018) From the embodied cognition to the embodied education in the physical and sports sciences, Encyclopaideia, 22 (51), pp. 11-24.

Ceciliani, A., Di Carlo, M., Tentoni, C. (2005) Mental process learning Medicina dello Sport, 58 (1), pp. 43-52.

D'Elia, F., Mazzeo, F., \& Raiola, G. (2018). The core curriculum in the university training of the teacher of physical education in Italy. Journal of Human Sport and Exercise, 13(2proc), S413-S420. https://doi.org/10.14198//hse.2018.13.proc2.25

D'isanto, T. (2019) Physical and sport education between Italian academic system and European Research Council structure panel, Journal of Human Sport and Exercise, 14, pp. S66-S76. https://doi.org/10.14198/ihse.2019.14.proc1.08

Di Tore, P.A., Raiola, G. (2012a) Exergame-design and motor activities teaching: An overview of scientific paradigms on motor control, Mediterranean Journal of Social Sciences, 3 (11), pp. 119122.

Di Tore, P.A., Raiola, G. (2012b) Exergames in motor skill learning, Journal of Physical Education and Sport, 12 (3), pp. 358-361.

D'Elia, F. (2019). The training of physical education teacher in primary school. Journal of Human Sport and Exercise, 14(1proc), S100-S104. https://doi.org/10.14198//hse.2019.14.Proc1.12

Raiola, G., D'Elia, F., \& Altavilla, G. (2018). Physical activity and sports sciences between European research council and academic disciplines in Italy. Journal of Human Sport and Exercise, 13(2proc), S283-S295. https://doi.org/10.14198/jhse.2018.13.proc2.13

Raiola, G. (2017) Motor learning and teaching method, Journal of Physical Education and Sport, 17, art. no. 236, pp. 2239-2243.

Raiola, G., Di Tore, P.A. (2017) Motor learning in sports science: Different theoretical frameworks for different teaching methods, Sport Science, 10, pp. 50-56.

Raiola, G. (2013) Body knowledge and motor skills, Knowledge Cultures, 1 (6), pp. 64-72.

Sanseviero, I., Cassese, F.P., Fonzo, E., Altavilla, G., D'elia, F. (2019) Study on the master's degree in sciences of sports evaluation and sport for disabled at the University of Salerno, Italy, Journal of

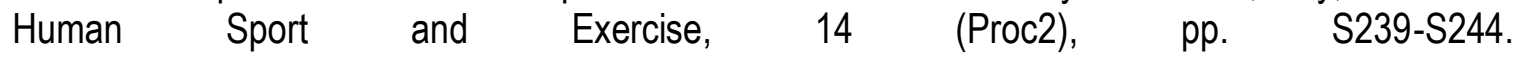
https://doi.org/10.14198/ihse.2019.14.proc2.12

Schmidt, R., A., Wrisberg, G., A., (2008), Motor Learning and Performance, Human Kinetics, Champain IL, USA.

Ministerial Decree 1 march 2004.

Ministerial Decree 16 march 2007.

Ministerial Decree 4 august 2000.

Law 28927 december 2002.

Ministerial Decree April 172003.

\section{(9) $(\mathbb{Q} \Theta \Theta$}

This work is licensed under a Attribution-NonCommercial-NoDerivatives 4.0 International (CC BY-NC-ND 4.0). 